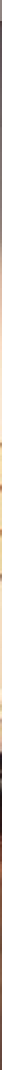

Último día del Taller Estrategias para enseñar con objetos y colecciones de museos. Dr. Alfonso Castrillón, Dr. William Crow y los participantes al taller. Foto: Renato Cáceres. 


\title{
Dime, muéstrame, involúcrame: la importancia de la enseñanza y el aprendizaje participativo en los museos
}

William B. Crow, PhD

Museo Metropolitano de Arte, Nueva York (EE. UU.) william.crow@metmuseum.org

\begin{abstract}
Resumen
Los museos y las instituciones culturales están buscando maneras para que sus visitantes estén más involucrados y conectados con sus instituciones. En lugar de ver a los visitantes del museo como receptores pasivos de información o experiencias, los museos y los visitantes del museo en sí, desean algo más. Este artículo ofrece ejemplos de la enseñanza y aprendizaje participativos, y por qué es importante para los museos y sus visitantes.
\end{abstract}

Palabras clave: museos, educación, estrategias para enseñar, Museo Metropolitano de Arte

\begin{abstract}
Museums and cultural institutions are looking for ways to make their visitors more involved and connected with their institutions. Instead of viewing museum visitors as passive recipients of information or experiences, museums, and museum visitors themselves, want something more. This article offers examples of participatory teaching and learning, and why it is important for museums and their visitors.
\end{abstract}

Keywords: Museums, education, teaching strategies, Metropolitan Museum of Art

\section{Introducción}

Cada vez más, los museos y las instituciones culturales están buscando maneras para que sus visitantes se involucren y conecten con sus instituciones. En lugar de ver a los visitantes del museo como receptores pasivos de información o experiencias, los museos, y los visitantes del museo en sí, desean algo más. Haciendo eco de la cultura en general, los individuos han ido más allá del hecho de ser consumidores y en su lugar han sido los productores. Ahora esperamos que no solo podamos personalizar nuestras experiencias, sino que puedan ser relevantes y participativas (Brown y Novak-Leonard, 2011).

Pero ¿cómo se ve esto en los museos? Y ¿cómo puede el personal del museo, así como los educadores del museo, invitar a los visitantes a participar e involucrarse con las colecciones de manera que sea emocionante, significativo y personalmente relevante? ¿Qué podemos hacer para involucrar a nuestros visitantes del museo activamente, sobre todo cuando estamos encargados de satisfacer las necesidades de un espectro tan diverso de visitantes? Y quizás lo más importante, ¿por qué molestarse? Después de todo, el compromiso implica algo activo, o incluso algo participativo, que puede llevar tiempo, recursos y una gran cantidad de esfuerzo. ¿Cuáles son los beneficios? 
En este artículo vamos a explorar algunas preguntas críticas que los museos deben responder.

¿Qué son la enseñanza y aprendizaje participativos y por qué son importantes?

¿Cómo se benefician los visitantes del museo de las prácticas de enseñanza y aprendizaje participativos?

¿Cuáles son algunos ejemplos de las mejores prácticas en los museos? ¿Cuáles son algunas estrategias que pueden ser utilizadas para involucrar a los visitantes del museo?

Antes de investigar estas cuestiones clave, podría ser útil compartir un poco de historia sobre mi propia experiencia como educador.

\section{Aprender a enseñar}

Cuando empecé mi carrera como profesor de preparatoria, recién salido de la universidad de pregrado, estaba lleno de energía y rebosante de ideas. Realmente quería darle a mis estudiantes experiencias increíbles para que ellos también salieran al mundo, inspirados para hacer el cambio y causar una diferencia, así que indagué en todos los cuadernos de preparatoria y la universidad, y reflexioné sobre todos los momentos que tuve con profesores que me habían inspirado.

Pero la verdad era que cuando recién empecé a darles clases a mis estudiantes de preparatoria nada parecía funcionar. Todos mis esfuerzos fracasaron. Los estudiantes no se veían comprometidos o siquiera interesados.

En el verano de 1996, decidí tomar un taller para educadores en el Museo Metropolitano de Arte. Pensé que tal vez este taller podría darme algunas ideas nuevas y ayudarme a conectar con los estudiantes. El taller fue codirigido por un educador del personal en el museo y un orador invitado, el filósofo y educador Maxine Greene. Pasamos un tiempo hablando de estrategias de enseñanza, durante la hora del almuerzo pude acercarme a él y conversar, le hablé de mis problemas con los estudiantes y de los ejercicios que estaba realizando, le mencioné también el esfuerzo que me costaba tratar de dar a estos estudiantes las mismas experiencias que tuve cuando era más joven. Entonces Maxine Greene me dijo: "Eso es lo que hiciste mal. Las experiencias no se pueden dar. Solo se pueden tener”.

¿Cómo podemos ayudar a los visitantes del museo a tener sus propias experiencias? ¿Cómo podemos involucrarlos como participantes activos en la construcción de significados sobre los objetos del museo? Esto puede significar que tengamos que enseñar de una manera distinta a como se nos enseñó, y qué tan dinámico y qué tantas enseñanzas diferentes pueden ayudar a todo tipo de visitantes a que tengan una exitosa y significativa visita al museo.

Como los museos tratan de reinventarse continuamente y promover su relevancia a los visitantes, puede ser útil examinar los orígenes de los museos. Un ejemplo es el de los fundadores del Museo Metropolitano de Arte (Nueva York, EE. UU.) en el siglo XIX, quienes imaginaron que este lugar no solo podría ser un sitio donde se coleccionan objetos de gran valor, sino también un lugar que podría dar forma a una ciudadanía más comprometida y participativa.

\section{Sobre el Museo Metropolitano de Arte}

El Museo Metropolitano de Arte posee una de las mayores colecciones universales de arte en el mundo, con más de dos millones de objetos de todos los periodos de tiempo y culturas. Pero en sus inicios, las fundaciones del museo eran mucho más modestas. En 1870, un grupo de artistas y patrocinadores se reunieron para iniciar un museo de arte. Fundaron el 


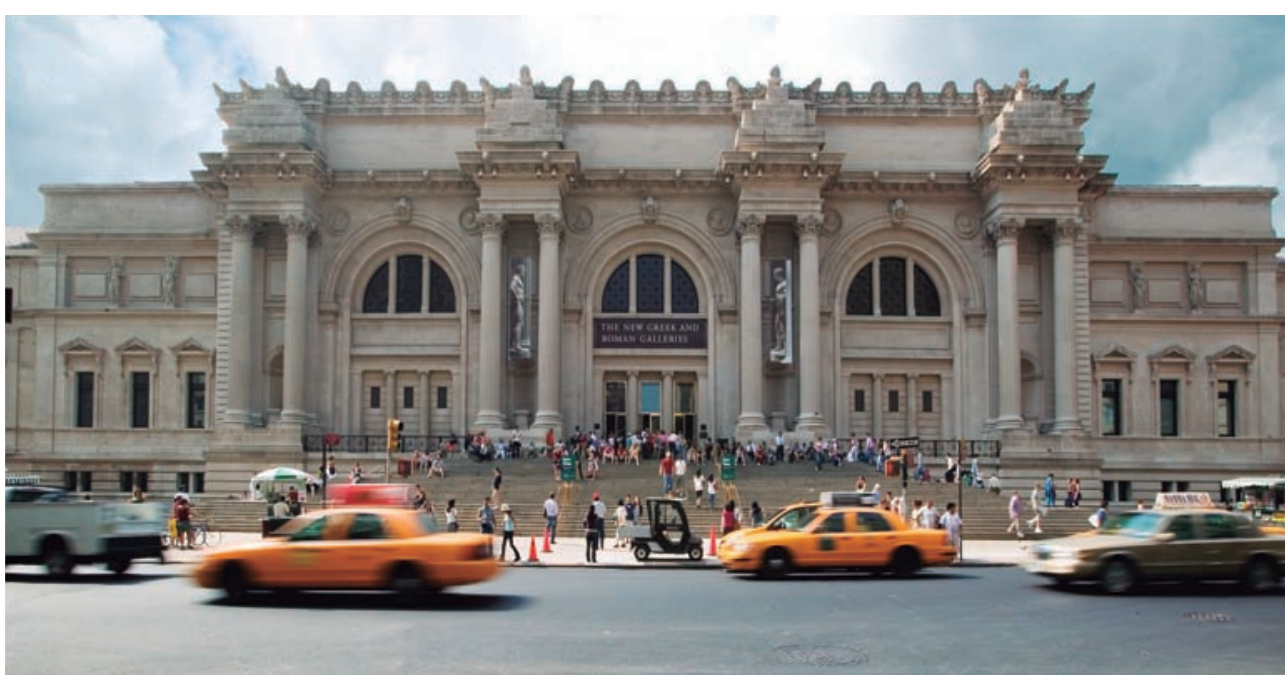

Fig. 1. Museo Metropolitano de Arte de Nueva York.

museo por muchas razones. Una de ellas fue que, en el entorno de finales del siglo XIX, la creciente industrialización de los Estados Unidos dio lugar a una gran riqueza y a la acumulación de grandes colecciones de arte. Familias como los Havemeyer, JP Morgan y Benjamin Altman necesitaban lugares para legar sus colecciones (Tomkins, 1970).

También es importante tener en cuenta los procesos de migración que traían nuevos ciudadanos a los Estados Unidos durante esa época. Estos nuevos ciudadanos hablaban diferentes idiomas, tenían diferentes culturas e intereses. Tanto los fundadores de museos en el siglo XIX en los Estados Unidos, junto con los educadores progresistas, entendieron que los museos podrían ser poderosos catalizadores educativos, incluso con estas barreras. En 1941, un gran educador de museo que trabajaba en el Museo Metropolitano de Arte, Theodore Low, escribió un libro llamado El museo como un instrumento social. Theodore Low postuló que el museo es un medio para crear el increíble cambio social y progreso, para apoyar y enriquecer a los ciudadanos y, en última instancia, abogar por una sociedad civil y democrática. Low escribió esto durante un tiempo de agitación mundial y guerra, y cuando los valores democráticos eran amenazados (Low, 1941).

\section{Cómo los visitantes de los museos se benefician de la enseñanza y aprendizaje participativo}

Como se mencionó anteriormente, invitar a los visitantes del museo a ser participantes activos en su propio aprendizaje puede ser un vehículo para la transformación de los museos de los almacenes del pasado a agentes activos del progreso social e, incluso, la construcción nacional. Pero ¿cómo se benefician directamente los propios visitantes del museo?

Sabemos por la investigación en el aprendizaje y en la ciencia cognitiva, que somos más propensos a recordar experiencias cuando involucran a múltiples sentidos y múltiples medios de procesamiento de la información. Si estamos de acuerdo en que queremos que las experiencias de los museos sean memorables, y queremos que duren y se queden con nosotros mucho tiempo después de salir de la presencia de un objeto del museo, tenemos que considerar cómo los museos deben pasar de ser proveedores pasivos de conocimientos a catalizadores para experiencias del cerebro completo.

Se ha convertido en un cliché de la cultura popular que podríamos decir que alguien no está utilizando todo su cerebro o no está pensando con todo su potencial. Es cierto que el 


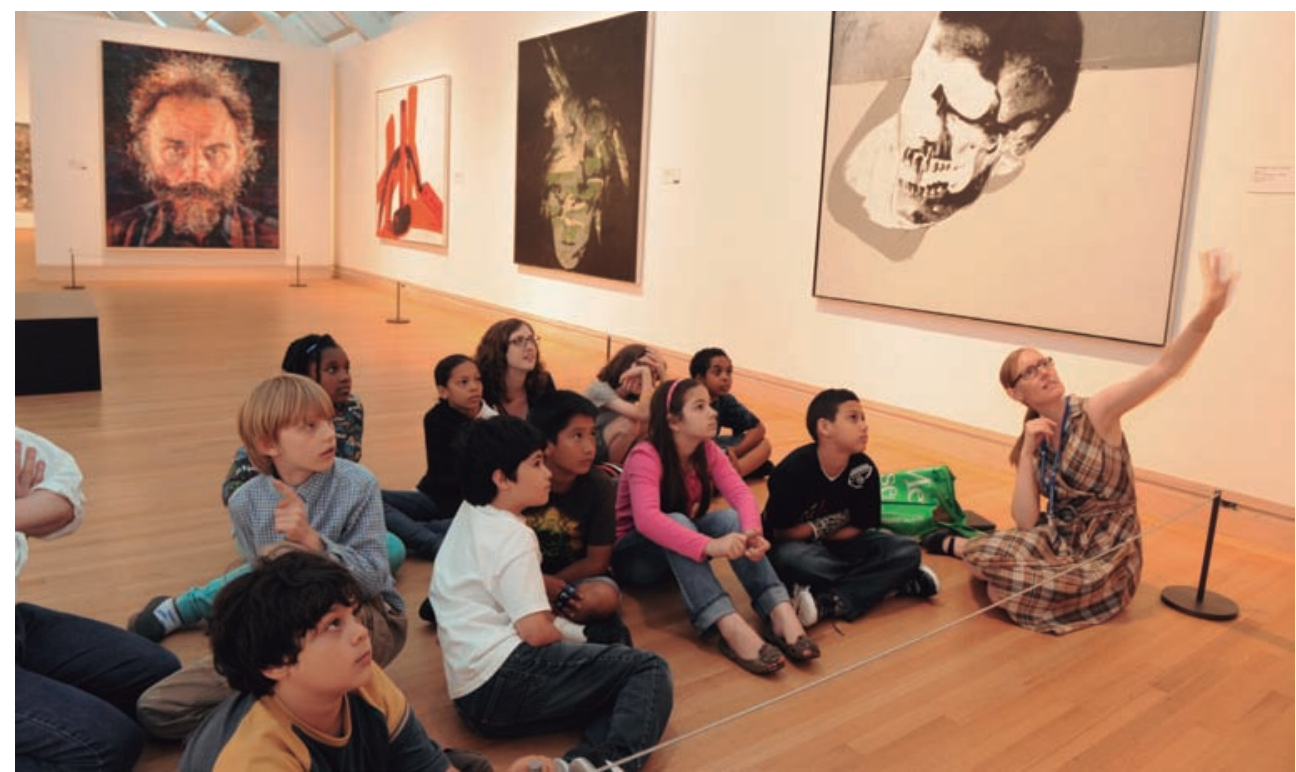

Fig. 2. Programas educativos. Foto: Filip Wolak.

cerebro humano tiene una gran cantidad de cosas en las cuales debe centrarse, en las funciones del cuerpo en curso, el procesamiento de todo tipo de información y luego, encima de todo eso, percibir y procesar nueva información.

Pero, para que nuestro cerebro esté realmente involucrado, y para que nosotros podamos tener recuerdos duraderos de nuestras experiencias, hay un par de cosas que tienen que suceder.

La primera es la exposición a la novedad. Hace años, un investigador llamado Magoun descubrió una de las partes más antiguas del cerebro humano en términos evolutivos. Esta parte, que ahora se llama el cerebro de Magoun, está escondida hacia el tronco cerebral, en la zona media del cerebro, y tiene como única función dar respuesta a la novedad en el medio ambiente. Como se cree, esta evolución se dio a partir de algunas preocupaciones muy importantes y prácticas, tales como la percepción de peligro. Los seres humanos que desarrollaron esta parte del cerebro eran más sensibles a los peligros en el entorno evolucionado, mientras que otros se convirtieron en la presa. Sin embargo, esta parte de nuestro cerebro sigue siendo muy importante. Todos hemos tenido la experiencia de aburrimiento cuando algo no está cambiando, es monótono y nada nuevo se está introduciendo. El cerebro de Magoun anhela la novedad, la sorpresa y la introducción de algo diferente. Cuando se activa, se comunica con el resto del cerebro y el cuerpo, el cual tiene que prestar atención. Todo se pone en estado de alerta (Schmidt, 2004).

Este aspecto primordial de la ciencia del cerebro se ve recientemente subrayado por la teoría de las inteligencias múltiples del Dr. Howard Gardner. En los años 1960 y 1970, Howard Gardner estaba haciendo una investigación en la Escuela de Educación de Graduados de la Universidad de Harvard. Se centró en un área llamada el desarrollo cognitivo, de hecho sus primeras investigaciones están muy centradas en las artes. Estudió los dibujos de niños e hizo estudios sobre cómo las personas se benefician de las artes. Posteriormente cambió su enfoque de investigación hacia el área de la inteligencia. Ahora, cuando la mayoría de nosotros pensamos acerca de la inteligencia, es probable que pensemos en dos letras: $\mathrm{CI}$, cociente intelectual. Pero Gardner desarrolló una teoría que ha sido adoptada por escuelas, 
educadores y museos en todo el mundo. Esta teoría, como tal vez muchas otras que salen de las escuelas de posgrado, en realidad es bastante simple: todos aprendemos de distintas maneras. En palabras de Gardner, todos tenemos no una, sino múltiples inteligencias, y todos las usamos en diferentes grados. Existen al menos nueve de estas inteligencias, que Gardner desarrolló a lo largo de varios años de investigación, desde inteligencia verbal y linguiística, a la inteligencia kinestésica, inteligencia interpersonal e intrapersonal, e incluso inteligencia natural (Gardner, 2008).

\section{Una necesidad de responder a los cambios demográficos}

Es importante reconocer que los visitantes del museo representan una amplia gama de datos demográficos y psicográficos, y estos están cambiando a un ritmo rápido, ya sea que nuestros visitantes del museo sean adultos o estudiantes, o las familias de todos sean diferentes. Ellos tienen sus propios orígenes, lenguas, culturas, necesidades de aprendizaje y formas de ver el mundo.

Un informe útil emitido por la Alianza Americana del Centro del Museo para el Futuro de los Museos es Museo y Sociedad 2034. El informe destaca los cambios clave que podemos esperar en la demografía de la población en el año 2034 como, por ejemplo, en los Estados Unidos, una de cada cinco personas tendrá más de 65 años de edad. Hoy ese número es 1 de cada 8. Tenemos una población que envejece de forma constante. Los museos pueden cambiar su trabajo para encontrar nuevas maneras de estimular a los visitantes mayores a través de la actividad cognitiva o, incluso, física. Los paneles de texto serán más grandes, el diseño universal se arraigará.

Para el 2034, los Estados Unidos se compondrá del 46 \% de poblaciones minoritarias en términos de etnicidad. Hoy ese número es $34 \%$. También debo decir que, en promedio, los museos solo ven que alrededor del $9 \%$ de sus visitantes son las poblaciones minoritarias. Por lo tanto, las cuestiones de lenguaje, diversas culturas, y diferentes valores y sistemas de creencias estarán en el primer plano de nuestro trabajo. También, como se sabe, hay muchas personas hoy en día y en el futuro, que se autoidentifican como personas con discapacidad física o de desarrollo. Algunas cifras: aproximadamente 1 de cada 88 personas son diagnosticadas con trastorno del espectro autista. Más de 3,5 millones de estadounidenses tienen alguna deficiencia visual severa. Alrededor de 600000 estadounidenses son legalmente ciegos. Cerca de 35 millones de estadounidenses tienen una capacidad reducida para distinguir los colores (Merritt, 2008).

\section{Estrategias para la enseñanza y el aprendizaje participativo en los museos}

\section{Usar temas o una cuestión central para estructurar las exposiciones y programas}

A menudo, cuando se visita un museo, o se participa en un programa de museo, nos enfrentamos a una enorme cantidad de información. Esto puede ser abrumador, incluso para los más experimentados asistentes a museos. Una respuesta puede volverse en frustración, agotamiento o, en el peor de los casos, en una sensación de molestia. La investigación muestra que el uso de un tema o esquema para organizar material complejo, ayuda a que los estudiantes se involucren con el material. Cada vez más, los museos pueden utilizar una pregunta central para una exposición o un programa para que los visitantes tengan una comprensión de lo que se está tratando y por qué es importante. Algunos ejemplos de preguntas centrales podrían ser: ¿qué hace un líder exitoso? o ¿cómo la gente anticuada responde a su entorno? A través de estos tipos de preguntas es que los visitantes pueden hacer conexiones relevantes con sus propios conocimientos y experiencias previas.

\section{Proporcionar a los visitantes del museo una elección dentro de la estructura}

Aunque un tema o cuestión central pueda proporcionar una estructura esencial dentro de una exposición en un museo o programa educativo, también es fundamental proporcionar 
a los visitantes del museo la elección. Esto puede significar permitir a los visitantes seleccionar una parte de su ruta o experiencia, o proporcionarles opciones, tales como un tiempo independiente dentro de una visita guiada. El elemento de elección es fundamental, ya que si nuestro objetivo es hacer a los museos relevantes y personalmente significativos para las personas que visitan, deben tener la oportunidad de expresar sus propios intereses y preferencias y, al hacerlo, que sean más propensas a crear experiencias memorables y agradables.

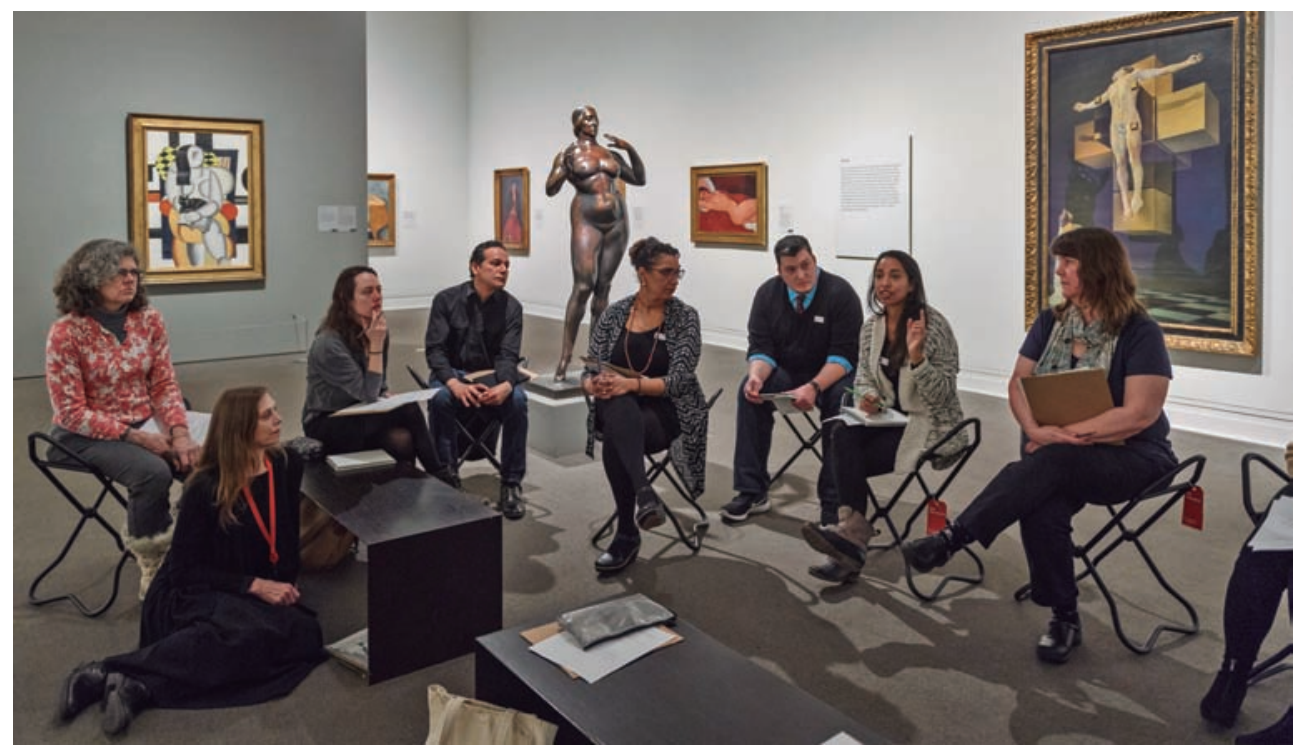

Fig. 3. Programas educativos del Met. Foto: Filip Wolak.

\section{Utilizar preguntas abiertas y enfoques basados en la investigación}

Mientras que muchos museos utilizan preguntas como un medio para activar la curiosidad del visitante, ya sea a través de textos didácticos en la pared de una exposición, o como una pregunta verbal articulada en un programa educativo, sabemos que no todas las preguntas son buenas. A menudo, las preguntas que hacemos son cerradas -que requieren una única respuesta correcta-. Hacer estas preguntas cerradas, tales como ¿qué tan largo es el río Nilo en Egipto? o ¿en qué año fue la revolución política?, no es útil para los visitantes del museo si nuestro objetivo es capacitarlos, apoyar su confianza y habilidades. En cambio, el uso de preguntas abiertas - preguntas que permiten muchos tipos diferentes de respuestas- ayudan a los visitantes a generar posibles respuestas, activa la solución creativa de problemas y les permite compartir sus propios puntos de vista y experiencias. Las preguntas abiertas del tipo ¿cómo describiría este objeto? o ¿qué notas en esta imagen? permiten que los visitantes participen de manera productiva.

\section{Oportunidades para aprender de forma social}

Los museos son lugares que sin duda podemos experimentar solos, pero muchas personas consideran una visita a un museo como una experiencia social con amigos, familiares y otros. Mi colega Lois Silverman escribió hace muchos años un libro llamado La obra social de los museos. Este libro tuvo origen en su tesis doctoral, en la que ella siguió diadas (pares) de visitantes de museo durante su visita para descubrir de qué hablaron. El resultado fue que el tema más frecuente de discusión entre pares en un museo es en realidad sobre sí mismos: hablan sobre ellos mismos (Silverman, 2010). 
Hay otra razón por la cual las experiencias sociales son una forma importante de hacer participar activamente a los visitantes, y es por esta idea: todos tenemos experiencia en compartir. Hace años, Edwin Hutchins, un psicólogo cognitivo de la Universidad de California, hizo algunos experimentos en los buques de guerra en San Diego. Él quería aprender cómo los grupos de personas toman las decisiones sobre estos grandes buques de mar, porque a menudo se requería que personas de diversos papeles proporcionaran información clave o, más bien, se necesitaban para que ofrecieran su propia experiencia, con el fin de llegar a la mejor decisión posible para el grupo. Esta investigación condujo a la idea de lo que ahora llamamos cognición distribuida, es decir, que podemos pensar como un grupo. De hecho, tocando la experiencia que existe entre todos los miembros de un grupo, no solo podremos atraer a estos visitantes, sino que aumentaremos los tipos de interpretaciones que estamos creando juntos acerca de los objetos de las colecciones en los museos (Hutchins, 1995).

Los educadores del museo son expertos en el aprendizaje social y el compromiso social en el museo. Cuando les preguntamos a los visitantes de dónde son, al comienzo de una visita guiada, o cuando los invitamos a hablar acerca de la característica de una escultura que ellos vieron, abrimos la puerta para que los visitantes del museo compartan sus intereses, conocimientos y experiencias.

\section{Conclusión}

Los museos e instituciones culturales ofrecen una enorme oportunidad para involucrar a la gente con ideas y temas que son relevantes -e incluso críticos- a su vida cotidiana. Sin embargo, si los visitantes del museo siguen siendo tratados como receptores pasivos de información o recipientes vacíos, vamos a perder la oportunidad de convertir los museos en algo esencial para las comunidades que servimos. A través de estrategias de enseñanza y de aprendizaje participativo, los museos pueden permitir que los visitantes se conviertan en participantes, creadores e intérpretes, en lugar de simples asistentes. Como se atribuye al gran erudito y filósofo chino, Confucio, el adagio nos dice:

“Dime, no me acuerdo. Muéstrame, lo recuerdo. Involúcrame, lo entiendo”.

\section{Referencias bibliográficas}

Brown, A. y Novak-Leonard y Jennifer L. (2011). ¿Cómo grupos de arte están creando oportunidades para la participación activa? La Fundación James Irvine.

Gardner, H. (2008). Inteligencias múltiples. La Teoría en Práctica. Basic Books.

Hutchins, E. (1995). Cognición en lo salvaje. Massachusetts: MIT Press.

Low, T. (1941). El museo como un instrumento social. Nueva York: Museo Metropolitano de Arte.
Merritt, E. (2008). Museos y Sociedad 2034. Alianza Americana de Museos.

Schmidt, L. (2004). Aula confidencial. Heinemann.

Silverman, L. (2010). La obra social de los museos. Routledge.

Tomkins, C. (1970). Comerciantes y obras maestras: La historia del Museo Metropolitano de Arte. Nueva York: Holt. 